\title{
Risk Spillovers in Returns for Chinese and International Tourists to Taiwan
} Chia-Lin Chang

Instituto

Complutense de Análisis Económico

Department of Applied Economics National Chung Hsing University, Taiwan

\author{
Department of Applied Economics Department of Finance \\ National Chung Hsing University, Taiwan
}

\section{Shu-Han Hsu}

Michael McAleer

Department of Finance Asia University, Taiwan and

Discipline of Business Analytics University of Sydney Business School,

Australia and Econometric Institute, Erasmus School of Economics

Erasmus University Rotterdam, The Netherlands

And Department of Economic Analysis and ICAE

Complutense University of Madrid, Spain and

Institute of Advanced Sciences Yokohama National University, Japan

\begin{abstract}
Fluctuations in the numbers of visitors directly affect the rates of return on tourism business activities. Therefore, maintaining a firm grasp of the relationship between the changes in the numbers of Chinese tourists and international travellers visiting Taiwan is conducive to the formulation of an effective and practical tourism strategy. Although the topic of international visitors to Taiwan is important, existing research has discussed the issue of the travel demand between Chinese tourists and international travellers visiting Taiwan. This paper is the first to examine the spillover effects between the rate of change in the numbers of Chinese tourist arrivals and the rate of change in the numbers of international traveller arrivals. Using daily data for Chinese tourists and international travellers visiting Taiwan over the period from 1 January 2014 to 31 October 2016, together with the Diagonal BEKK model, the paper analyses the co-volatility spillover effects between the rate of change in the numbers of international travellers and the rate of change in the numbers of Chinese tourists visiting Taiwan. The empirical results show that there is no dependency relationship between the rate of change in the numbers of Chinese tourists and the rate of change in the numbers of international travellers visiting Taiwan. However, there is a significant negative co-volatility spillover effect between the rate of change in the numbers of Chinese tourists and the rate of change in the numbers of international travellers. The empirical findings suggest that Taiwan should abandon its development strategy of focusing only on a single market, namely China, and to be pro-active in encouraging visits by international travellers to Taiwan for sightseeing purposes, thereby increasing the willingness of international travellers to visit Taiwan. Moreover, with the reduction in the numbers of Chinese tour groups visiting Taiwan, and increases in the numbers of individual travellers, the Taiwan Government should change its previous travel policies of mainly attracting Chinese tour group travellers and actively promoting in-depth tourism among international tourists, by developing tourism that focuses on the special characteristics of different localities. In this way, the government can enhance the quality of Taiwan's tourism, and also attract travellers with high spending power.
\end{abstract}

Keywords Risk spillovers, International tourism arrivals, Chinese tourist arrivals, Group tourists, Individual tourists, Medical tourists, Co-volatility effects, Diagonal BEKK model.

JEL Classification Z Z32, Z33, C22, C32, C58.

\section{Working Paper no 1811}

March, 2018

UNIVERSIDAD

COMPLUTENSE

MADRID

ISSN - 2341-2356

WEB DE LA COLECCIÓN: http://www.ucm.es/fundamentos-analisis-economico2/documentos-de-trabajo-del-icaeWorking papers are in draft form and are distributed for discussion. It may not be reproduced without permission of the author/s. 


\title{
Risk Spillovers in Returns for Chinese and International Tourists to Taiwan*
}

\author{
Chia-Lin Chang \\ Department of Applied Economics \\ Department of Finance \\ National Chung Hsing University, Taiwan \\ Shu-Han Hsu \\ Department of Applied Economics \\ National Chung Hsing University, Taiwan \\ Michael McAleer \\ Department of Finance \\ Asia University, Taiwan \\ and \\ Discipline of Business Analytics \\ University of Sydney Business School, Australia \\ and \\ Econometric Institute, Erasmus School of Economics \\ Erasmus University Rotterdam, The Netherlands \\ and \\ Department of Economic Analysis and ICAE \\ Complutense University of Madrid, Spain \\ and \\ Institute of Advanced Sciences \\ Yokohama National University, Japan
}

March 2018

* For financial support, the first author wishes to thank the Ministry of Science and Technology (MOST), Taiwan, and the third author acknowledges the Australian Research Council and the Ministry of Science and Technology (MOST), Taiwan. 


\begin{abstract}
Fluctuations in the numbers of visitors directly affect the rates of return on tourism business activities. Therefore, maintaining a firm grasp of the relationship between the changes in the numbers of Chinese tourists and international travellers visiting Taiwan is conducive to the formulation of an effective and practical tourism strategy. Although the topic of international visitors to Taiwan is important, existing research has discussed the issue of the travel demand between Chinese tourists and international travellers visiting Taiwan. This paper is the first to examine the spillover effects between the rate of change in the numbers of Chinese tourist arrivals and the rate of change in the numbers of international traveller arrivals. Using daily data for Chinese tourists and international travellers visiting Taiwan over the period from 1 January 2014 to 31 October 2016, together with the Diagonal BEKK model, the paper analyses the co-volatility spillover effects between the rate of change in the numbers of international travellers and the rate of change in the numbers of Chinese tourists visiting Taiwan. The empirical results show that there is no dependency relationship between the rate of change in the numbers of Chinese tourists and the rate of change in the numbers of international travellers visiting Taiwan. However, there is a significant negative co-volatility spillover effect between the rate of change in the numbers of Chinese tourists and the rate of change in the numbers of international travellers. The empirical findings suggest that Taiwan should abandon its development strategy of focusing only on a single market, namely China, and to be pro-active in encouraging visits by international travellers to Taiwan for sightseeing purposes, thereby increasing the willingness of international travellers to visit Taiwan. Moreover, with the reduction in the numbers of Chinese tour groups visiting Taiwan, and increases in the numbers of individual travellers, the Taiwan Government should change its previous travel policies of mainly attracting Chinese tour group travellers and actively promoting in-depth tourism among international tourists, by developing tourism that focuses on the special characteristics of different localities. In this way, the government can enhance the quality of Taiwan's tourism, and also attract travellers with high spending power.
\end{abstract}

Keywords: Risk spillovers, International tourism arrivals, Chinese tourist arrivals, Group tourists, Individual tourists, Medical tourists, Co-volatility effects, Diagonal BEKK model.

JEL: Z32, Z33, C22, C32, C58. 


\section{Introduction}

With the rising tide of globalization, international exchanges and interactions are becoming increasingly frequent, and the international tourism industry is developing more and more rapidly. Taiwan's particular terrain and superior geographical location have led to a rich and varied natural landscape and ecological resources, together with a unique scenery and culture. According to the Travel and Tourism Competitiveness Report published by the World Economic Forum (WEF) in January 2017, Taiwan was ranked $30^{\text {th }}$ overall among 136 countries and areas in terms of the Travel and Tourism Competitiveness Index (which encompasses an "enabling environment”, "travel \& tourism policy and enabling conditions", "infrastructure" and "natural and cultural resources"), $16^{\text {th }}$ in regard to its ground and port infrastructure, and $28^{\text {th }}$ in terms of its safety and security.

As a consequence of the large-scale liberalization of Cross-Strait tourism policies in 2008, the numbers of Chinese tourists visiting Taiwan have continued to rise. In 2010, China leapfrogged over all other countries to become the largest source country of international tourists to Taiwan (although both Taiwan and China regard tourists in each direction as domestic tourists). By the end of 2015, the numbers of tourists from China visiting Taiwan had reached 3.43 million, or $45.8 \%$ of the total numbers of foreign tourists, with China thereby becoming the major country affecting the development of Taiwan’s tourism economy (Taiwan Tourism Bureau, 2017). The growth in the numbers of international tourists has indirectly led to an increase in foreign exchange earnings from tourism, with 10.69 million international arrivals in Taiwan in 2016 (an increase of $2.4 \%$ as compared with 2015), and an estimated foreign exchange income from tourism of about 13.374 billion US dollars (UNWTO, 2017). 
According to statistics compiled by the Tourism Bureau of the Ministry of Transportation and Communications (MOTC), the total number of international travellers visiting Taiwan for sightseeing purposes rose from 1,775,200 in 2008 to $7,560,700$ in 2016. The direct contribution of tourism to Taiwan's GDP reached 2.0\% (or growth rate of $0.5 \%$ ), leading to an increase in capital investment of NT\$5.9 billion (representing a growth rate of $1.5 \%$ ), and accounting for $2.6 \%$ of employment opportunities (up by 4.0\%) (WTTC, 2017).

In addition, from 2008 to 2016, foreign exchange revenues from tourism increased sharply from NT\$5.936 billion to NT\$13.374 billion, reflecting an annual compound growth rate of $10.69 \%$, which is much higher than the $5.95 \%$ recorded over the 2000-2008 period, and resulting in a large amount of foreign exchange earnings for Taiwan (see Figure 1). The ratio of Chinese tourists to the total number of international travellers also rose from 5.34\% (or 947,600 visitors) in 2008 to 37.64\% (or 2,845,500 visitors) in 2016 (see Figure 2).

[Figures 1 and 2 go here]

International visitors to Taiwan in 2016 mostly came from six regions, namely China, Hong Kong and Macao, Japan, South Korea, Singapore, Malaysia and USA. Compared with the numbers of tourists who visited Taiwan in 2015, South Korea achieved the highest growth of $36.4 \%$, followed by Japan with $16.14 \%$ and the USA with $16 \%$.

International travellers are driving the development of the local economy in Taiwan. The main tourism spots that travellers from abroad visit include the night markets, Taipei 101 (which held the record as the world's tallest building from 31 December 2004 to 4 January 2010, and is currently the fifth tallest building in the world), National Palace Museum (Taipei), Chiang Kai-shek Memorial Hall (Taipei), 
Sun Yat-sen Memorial Hall (Taipei), Jiufen (Danshui-Taipe), Sun Moon Lake (Nantou County), Kenting National Park (located on the Hengchun Peninsula of Pingtung County), and Taroko Gorge National Park (Hualien County), all of which have been attracting large numbers of tourists.

The numbers of travellers from China visiting Taiwan are closely related to the political relations across the Taiwan Strait. As the political positions and political environment on the two sides of the Taiwan Strait change, non-governmental exchanges between the two are indirectly affected. This is especially so when there are conflicts between Taiwan and China, and when there is an increased awareness of Taiwan's sovereign independence in the former, and a greater push for territorial reunification in the latter. At such times, sensitivities between the two sides are heightened and this, in turn, may affect the willingness of Chinese tourists to travel to Taiwan.

In addition, with the huge increase in the numbers of Chinese tourists visiting Taiwan, the ability of Taiwan's tourism industry and the local environment to handle and support so many visitors has gradually been surpassed. It has also led to controversies and rumors that the quality of tourism in Taiwan is deteriorating, and driving other international travellers away from Taiwan. Therefore, although the data show that the numbers of international travellers visiting Taiwan has been increasing on an annual basis, the foreign exchange earnings from sightseeing tourism have exhibited a downward trend since 2015. As the numbers of tourists from China have declined, the numbers of tourists in the major sightseeing spots have also fallen which, in turn, seems to have had an impact on the businesses surrounding the tourist attractions.

According to the "Survey Report on Visitors’ Expenditure and Trends in Taiwan” prepared by the MOTC’s Tourism Bureau, the average spending per person per day 
for travellers visiting Taiwan has been the highest among tourists from Japan, followed in second place in terms of spending by Chinese tourists. However, spending by Chinese travellers accounts for roughly one-half, on average, of total tourism expenditure in Taiwan, so that they are ranked first in terms of overall expenditures among international visitors to Taiwan.

In terms of the items that are consumed or purchased, there are differences in consumption characteristics between Chinese tourists and other international travellers, in that international tourists tend to attach greater importance to leisure and culture, and exhibit a relatively strong demand for quality accommodation and surrounding facilities. For example, expenditure on hotel accommodation by tourists from Japan, USA and Europe accounts for between $45 \%$ and $50 \%$ of their total tourism expenditures. Travellers from South Korea and Singapore spend about 40\% of their total travel expenditure on hotel accommodation, with purchases of mostly local products and specialty products accounting for the major share of their expenditure. In addition, spending on food and entertainment by Japanese travellers is much higher, on average, than for visitors from other countries, indicating that Japanese tourists are more willing to pay to experience Taiwanese food and culture.

On the contrary, Chinese tourists are less demanding when it comes to the quality of accommodation and eating. In terms of their shopping expenditures, in addition to purchasing local products and specialty products, Chinese tourists spend a large proportion of their money on fine clothes, jewellery, jadeware, and cosmetics and perfumes (Taiwan Tourism Bureau, 2017).

As international travellers tend to pay higher fees for accommodation, operators of high-priced hotels (international tourist hotels) are less affected by changes in the numbers of Chinese tourists visiting Taiwan. Chinese tourists, on the other hand, are less willing to spend large amounts on accommodation and food, and are more 
inclined to be part of tour groups when visiting Taiwan. For this reason, reductions in the numbers of Chinese tourists have a greater impact on retailers, lower-priced hotels, and related tour operators in Taiwan.

In spite of the assertion of goodwill and maintenance of peace on both sides of the Taiwan Strait after the Democratic Progressive Party (DPP) took over governing powers from the Kuomintang (KM T) in Taiwan in 2016, President Tsai Ing-Wen did not clearly articulate the One-China principle, as demanded by the people's republic of China. This lead to official dissatisfaction on the part of the Chinese Government, among them being rumors that China limited the numbers of Chinese tourists who can visit Taiwan. The statistical data indicate that the numbers of Chinese tourists visiting Taiwan have indeed decreased significantly.

For instance, the number of Group-type travellers declined by 7.21\% in 2015 and by $29.95 \%$ in 2016, while the number of Medical-type travellers fell by one-half. The number of Individual-type travellers has also decreased slightly, and the decline in visitor arrivals has also directly affected Taiwan’s foreign exchange earnings from tourism, with such revenues falling by 1.55\% in 2015 and by $7.05 \%$ in 2016 (National Immigration Agency of Taiwan, 2017; Taiwan Tourism Bureau, 2017). International tourists have not been affected by the political influence brought to bear by the change in the National Government and, as of the end of 2016, the total number of such visitors was continuing to rise.

The decrease in the number of Chinese tourists visiting Taiwan has hit the tourism-related industries in Taiwan, especially tour operators, tour bus companies, businesses providing night-time snacks, more budget-conscious hotels, and boutiques that are close to the major tourist attractions. On 12 September 2016, tourism-related enterprises in Taiwan formed a "self-help society for the millions in the tourism industry", and demonstrated in the streets, while demanding that the government 
propose appropriate response policies to enable them "to survive, work, and have enough food and clothing.”

In order to encourage Chinese and international tourism, the "Self-help Society for the Millions in the Tourism Industry” was organized by the General Chamber of Commerce of the Republic of China, the ROC Tourist Hotels Business Association, the ROC Federation of Travel Agents, the ROC National Federation of Hotels, the National Federation of ROC Tour Buses, the ROC Tourist Guide Association, the ROC Association for Quality Products, the Taiwan Bed \& Breakfast Association, the Taiwan Tourism Recreation Area Association, the Taipei Business District and Industrial Confederation, the Hot Spring Tourism Association Taiwan, and the Taiwan Brilliant Tourism Association.

Changes in the numbers of tourists can lead to many uncertainties. Changing the numbers of visitors directly affect the rates of return on tourism business activities. Therefore, maintaining a firm grasp of the relationship between changes in the numbers of Chinese tourists and international travellers visiting Taiwan is conducive to the formulation of a practical and efficient tourism strategy, which, in turn, will affect the economic benefits accruing to Taiwan's tourism industry and the economy more generally.

Although the topic of international visitors to Taiwan is important, existing research has discussed the issue of travel demand between Chinese tourists and international travellers visiting Taiwan. This paper is the first to examine the spillover effect between the rate of change in the numbers of Chinese tourist arrivals and the rate of change in the numbers of international traveller arrivals. The paper also decomposes, for the first time, Chinese tourists into three distinct categories, namely Group-type, Individual-type. and Medical-type categories, in order to compare the extent and magnitude of the fluctuations in risk between the different types of Chinese 
and international travellers.

The applications of multivariate conditional variability models in the past are too numerous to mention, but almost none of the extant literature has been concerned with whether or not these multivariate conditional variability models conform to statistical properties for consistency and asymptotic normality, so that the empirical results obtained contained many wrong explanations.

This paper uses the fundamental equation in tourism finance established by McAleer (2015) to link the rate of return on tourism revenues to the rate of change in the numbers of tourists. The paper also uses the multivariate Diagonal BEKK conditional volatility model that has known mathematical regularity conditions and valid asymptotic statistical properties to analyse the volatility spillover effects between the rate of change in the numbers of Chinese tourists and the rate of change in the numbers of international visitors.

Applying quantitative finance methods to issues in the tourism economy, and analysing the risk and volatility in relation to the different groups of Chinese tourists and international travelers, is helpful in understanding the impact of changes in the number of tourists visiting Taiwan on the Taiwan economy. The empirical findings in this paper can serve as a useful reference to the Taiwan Government for its policy-making regarding tourism in the future.

The remainder of the paper is organized as follows. Section 2 presents a literature review of tourism spillover effects. Section 3 discusses the models, including the fundamental equation in tourism finance. The variables and data are described in Section 4. Section 5 provides an analysis of the empirical results. Some concluding comments are given in Section 6.

\section{Literature Review of Tourism Spillover Effects}


Spillover effects, which are widely used in research in empirical finance and cognate disciplines, measure the transfer of risk between financial products, thereby helping investors to forecast their returns vis-à-vis risk and allocate their investment products optimally. The changes in the numbers of international travellers in the tourism market are just as uncertain and risky as are the changes in the returns in financial markets. In the past, conditional volatility models have been used in tourism finance to analyse the changes in the numbers of tourist arrivals. In this section, we discuss the issues surrounding spillover effects in relation to the risks associated with tourism revenues.

Chan et al. (2005) analyse the effect of fluctuations in risk in relation to the demand for travellers visiting Australia from Japan, New Zealand, UK and USA over the period July 1975 to December 2000. They use the constant conditional correlation (CCC), VARMA-GARCH and VARMA-AGARCH models to estimate the effects of fluctuations in risk. The empirical results show that there exist cross-country interdependent effects in regard to the demand for tourism between Japan and UK, Japan and USA, and New Zealand and USA. In addition, the authors also find evidence of asymmetric effects in relation to the risk volatility of travel demand for both Japan and New Zealand.

In exploring the spillover effects between tourism growth and country risk premiums for small island tourism economies (SITEs), Hoti et al. (2007) use tourist arrivals in Cyprus and Malta covering the period from May 1996 to May 2002, as well as composite country risk ratings published monthly by the International Country Risk Guide (ICRG). Hoti et al. (2007) also use the VARMA-GARCH and VARMA-AGARCH models to estimate the spillover effects in relation to risk fluctuations. The empirical results show that tourism growth in Cyprus has a 
significant positive risk spillover effect on the growth of tourism in Malta, while the country risk premium between Cyprus and Malta exhibits an interdependence effect. There is also a significant negative risk spillover effect between tourism growth in Cyprus and its country risk premium. There is, however, no risk spillover effect between Malta's tourism growth in Malta and its country risk premium.

In relation to SITEs, Shareef and McAleer (2008) use the VARMA-GARCH model to explore the risk spillover effects between the Maldives and the Seychelles regarding tourism demand emanating from source countries that provided tourists to these destinations between January 1994 and December 2003. The empirical results show that cross-country risk spillover effects from the Seychelles to the Maldives are greater than those from the Maldives to the Seychelles. Therefore, the tourism demand for the Seychelles affects the tourism demand for the Maldives in a significant way.

In analysing the monthly departures of South Korean tourists from Korea to the Philippines, Singapore and Thailand, as opposed to those going to Jeju Island over the period from April 1980 to June 2006, Seo et al. (2009) examine the risk spillover effects in relation to the tourism demand created by these tourists. Using a dynamic conditional correlation (DCC) model to estimate these risk spillover effects, the empirical results show that the risk spillover effects for tourism demand between Jeju Island and the Philippines, Singapore and Thailand are negatively correlated. This finding indicates that there is a substitution effect for tourism demand, especially in South Korea beginning in 1988 when, following the implementation of the Liberalization of the Travel Code policy, controls on outbound travel from South Korea were relaxed until the 1997 Asian financial crisis. During this period, there is a significant increase in travel demand by South Koreans to visit the Philippines, Singapore and Thailand which, in turn, reduced the travel demand for visits to Jeju 
Island.

Using the CCC, VARMA-GARCH and VARMA-AGARCH models to estimate the risk spillover effects, Chang et al. (2011) examine the travel demand for ASEAN countries. Using monthly data on inbound travellers for four major South-East Asian countries, namely Indonesia, Malaysia, Singapore and Thailand, from January 1997 to July 2009, the empirical results show that there is evidence of volatility spillover effects for the country pairs Thailand and Malaysia, Thailand and Singapore, Singapore and Indonesia, Singapore and Malaysia, and Indonesia and Malaysia, but not for Thailand and Indonesia.

In order to examine the existence of risk spillover effects between tourism demand and the exchange rate, Akar (2012) uses the DCC model to estimate the risk spillover effects of the number of visits by travellers from the Eurozone, UK and USA to Turkey, and monthly exchange rate data (Turkish Lira/Euro, Turkish Lira/Sterling, and Turkish Lira/ US dollar) from January 2001 to November 2011. The empirical results indicate that there is a positive spillover effect between travel demand and the exchange rate for visitors from the Eurozone and USA. When the exchange rate increases, tourism demand on the part of those travellers from the Eurozone countries and USA visiting Turkey also increase. However, no such risk spillover effect is found to exist between tourism demand and exchange rate on the part of travellers from the UK.

In another study that also examines the spillover effects between tourism demand and the exchange rate, Yap (2012) uses data covering the period from January 1991 to January 2011 based on the number of visits by travellers from China, India, Japan, Malaysia, New Zealand, Singapore, South Korea, UK and USA, and monthly exchange rate data for each currency relative to the Australian dollar. The risk spillover effects are estimated using the CCC, VARMA-GARCH and 
VARMA-AGARCH models. The empirical results show that the persistence of the impact of exchange rate shocks on tourism demand gradually decrease over time, and that there is only a weak relationship between the exchange rate and tourism demand. These empirical results indicate that tourism demand on the part of travellers to Australia is affected only slightly by exchange rates.

In evaluating how a country's geographic location might influence the spillover effects for inter-regional tourism demand, Balli et al. (2015) use a multivariate GARCH model to estimate the risk spillover effects. The authors analyse the inter-regional spillover effects for inter-regional tourism demand for New Zealand's main tourist attractions (Auckland, Wellington and Canterbury), and 32 of New Zealand's regional tour organizations (RTOs), for the period from January 2007 to May 2013. They use variance ratios to estimate the impact of the fluctuations in tourism demand for these major tourist attractions on the fluctuations in the demand for tourism among the RTOs. The empirical results show that the inter-regional spillover effects of the major tourist attractions and the RTOs in New Zealand are significant, and also indicate the size of the impacts. In addition to the proximity of geographical locations, the paper also examines whether there are scheduled flights between the RTOs and the major tourist destinations that might also impact the inter-regional spillover effects between two different regions.

In a further study on the inter-regional spillover effects for international tourism demand in Australia and New Zealand, Balli and Tsui (2016) use a bivariate GARCH model to estimate the risk spillover effects using data on the monthly arrivals of international travellers to Australia and New Zealand from Canada, China, Germany, Japan, Korea, UK and USA from 2000 to 2012. The results show that the tourism demand of travellers from East Asia (China and Japan) visiting New Zealand have a significant spillover effect on the tourism demand of travellers visiting Australia. In 
addition, tourism demand for travellers from Western countries (Canada, Germany and the U.S.) visiting Australia have significant spillover effects on New Zealand's tourism demand, while the tourism demand for UK travellers visiting New Zealand and Australia is found to have significant symmetrical spillover effects.

Valadkhari et al. (2017) investigate the interdependence and risk volatility of the spillover effects resulting from Australia's inbound and outbound visitor traffic. The authos use monthly data on the arrivals and departures of visitors to Australia from 49 countries for the period from January 1991 to July 2014, and a multivariate GARCH model, to estimate the risk spillover effects. The results show that there is interdependence among international travellers from countries including Brazil, China, India and Indonesia. Fluctuations in the numbers of inbound and outbound passengers from China, Hong Kong, Papua New Guinea, Singapore, South Africa and the UK are found to have significant spillover effects, implying that changes in the numbers of arriving and departing visitors from these countries indirectly cause risks to fluctuate. This is likely to have adverse effects on Australia’s tourism market.

From the research findings presented above, it can be seen that the analysis of spillover effects in the context of tourism-related issues has focused mainly on tourism spillover effects between different countries, cities or regions, in order to explain the changes and interrelationships in tourism demand among countries, cities or regions. In this paper, the issue of the impact of volatility in tourism demand between Chinese tourists and other international travellers visiting Taiwan is discussed in terms of changes in the rate of growth of tourist arrivals and their corresponding volatility. In what follows, we briefly introduce the multivariate conditional volatility model specification that will be used in the empirical analysis.

\section{Model Specifications}


In order to capture volatility spillover effects, numerous papers in empirical research use multivariate conditional volatility models to estimate conditional covariances. The most widely used models include the constant conditional correlational (CCC) model of Bollerslev (1990), the Baba, Engle, Kraft, and Kroner (BEKK) multivariate GARCH model of Baba et al. (1985) and Engle and Kroner (1995), the dynamic conditional correlation (DCC) model of Engle (2002), the vector ARMA-GARCH (VARMA-GARCH) model of Ling and McAleer (2003), and the VARMA-asymmetric GARCH (VARMA-AGARCH) model of McAleer et al. (2009). For further details these and other leading multivariate conditional volatility models, see McAleer (2005) and Chang et al. (2018).

Despite the popularity and wide use of multivariate conditional volatility models in empirical finance, there are theoretical problems associated with virtually all of them. The CCC, VARMA-GARCH and VARMA-AGARCH models have static conditional covariances and correlations, which means that accommodating volatility spillovers is not possible (see McAleer et al., 2008). Moreover, the Full BEKK and DCC models have been shown to have no regularity conditions, and hence no asymptotic properties of consistency and asymptotic normality (for further details, see McAleer and Hafner, 2014; Chang and McAleer, 2018; McAleer, 2018). Therefore, this paper uses the Diagonal BEKK (DBEKK) model to estimate the volatility spillover effects as DBEKK has known regularity conditions and asymptotic properties.

In Section 3.1, we discuss the DBEKK multivariate conditional volatility model (for further details, see McAleer et al. (2008), Chang et al. (2015) and Chang et al. (2018); for univariate conditional volatility models, see Engle (1982), Tsay (1987), Ling and McAleer (2003), McAleer (2014), and Chang and McAleer (2017)). In 
Section 3.2, we define co-volatility spillovers and the test of the null hypothesis of volatility spillover effects. In order to link the rate of returns on tourism revenue to the rate of change in the numbers of tourists, we present McAleer's (2015) fundamental equation in tourism finance in Section 3.3.

\subsection{Diagonal BEKK Model}

The multivariate extension of the univariate ARCH and GARCH models is presented in Baba et al. (1985) and Engle and Kroner (1995) (see also Chang and McAleer (2018)). The multivariate extension of equation (1) can remain unchanged by assuming that the three components are each $m \times 1$ vectors, where $m$ is the number of financial assets, as given below:

$$
R_{t}=E\left(R_{t} \mid I_{t-1}\right)+\varepsilon_{t}
$$

where $R_{t}=\left(R_{1 t}, \ldots R_{m t}\right)^{\prime}$, and $\varepsilon_{t}=\left(\varepsilon_{1 t}, \ldots \varepsilon_{m t}\right)^{\prime}$.

For establishing volatility spillovers in a multivariate framework, it is useful to define the multivariate extension of the relationship between the return shocks and the standardized residuals, as follows:

$$
\varepsilon_{t}=D_{t}^{1 / 2} \eta_{t}
$$

where $D_{t}=\operatorname{diag}\left(h_{1 t}, \ldots, h_{m t}\right)$ is a diagonal matrix comprising the univariate conditional volatilities, and $\eta_{t}$ is an $m \times 1$ vector that is assumed to be iid for all $m$ elements, $\eta_{t}=\left(\eta_{1 t}, \ldots \eta_{m t}\right)^{\prime}$.

The conditional correlation matrix of $\varepsilon_{t}$ as $Q_{t}$, which is equivalent to the conditional correlation matrix of $\eta_{t}$, is given by $\Gamma_{t}$. Therefore, the conditional expectation of equation (2) is defined as:

$$
Q_{t}=D_{t}^{1 / 2} \Gamma_{t} D_{t}^{1 / 2}
$$

Equivalently, the conditional correlation matrix, $\Gamma_{t}$, can be defined as:

$$
\Gamma_{t}=D_{t}^{-1 / 2} Q_{t} D_{t}^{-1 / 2}
$$


Equation (3) is useful if a model of $\Gamma_{t}$ is available for purposes of estimating $Q_{t}$, whereas equation (4) is useful if a model of $Q_{t}$ is available for purposes of estimating $\Gamma_{t}$. As the elements of $D_{t}$ are consistent and asymptotically normal, the consistency of $Q_{t}$ in equation (3) depends on consistent estimation of $\Gamma_{t}$, whereas the consistency of $\Gamma_{t}$ in equation (4) depends on consistent estimation of $Q_{t}$. As both $Q_{t}$ and $\Gamma_{t}$ are products of matrices, with inverses in equation (4), neither the QMLE of $Q_{t}$ nor of $\Gamma_{t}$ will be asymptotically normal, based on the definitions given in equations (3) and (4). In short, the asymptotic properties are unknown.

In order to derive the DBEKK model, McAleer et al. (2008) used an extension of the Tsay (1987) univariate RCA process, namely the vector random coefficient autoregressive process of order one, which is given as:

$$
\begin{aligned}
& \varepsilon_{t}=\Phi_{t} \varepsilon_{t-1}+\eta_{t} \\
& \Phi_{t} \sim \operatorname{iid}(0, A) \\
& \eta_{t} \sim \sim \operatorname{iid}(0, C)
\end{aligned}
$$

where $\varepsilon_{t}$ and $\eta_{t}$ are $m \times 1$ vectors, $\Phi_{t}$ is an $m \times m$ matrix of random coefficients, $A$ is a diagonal matrix, $\mathrm{A}=\mathrm{a} I_{m}$, and $C$ is an $\mathrm{m} \times \mathrm{m}$ matrix.

If $\mathrm{A}$ is a full matrix, the Full BEKK model cannot be derived from any known underlying stochastic processes, which means there are no regularity conditions and hence also no valid asymptotic properties of QMLE of the associated parameters, except by assumption (for further details, see Chang et al, 2018; Chang and McAleer, 2018). Moreover, as estimation of the Full BEKK model involves $3 m(m+1) / 2$ parameters, the "curse of dimensionality" will be likely to arise, which means that convergence of the estimation algorithm becomes problematic and less reliable when there is a large number of parameters to be estimated (for further details, see Chang et al., 2018). 
Therefore, in the empirical analysis, in order to investigate volatility spillover effects, the DBEKK model will be estimated. McAleer et al. (2008) show that the multivariate extension of $\operatorname{GARCH}(1,1)$ from equation (5) is given as the diagonal BEKK model, namely:

$$
Q_{t}=C C^{\prime}+A \varepsilon_{t-1} \varepsilon_{t-1}^{\prime} A^{\prime}+B Q_{t-1} B^{\prime}
$$

where $A$ and $B$ are both diagonal matrices, with $a_{i i}>0$ for all $i=1, \cdots, m$, $\left|b_{j j}\right|<1$ for all $j=1, \cdots, m$, and $\varepsilon_{t-1} \varepsilon_{t-1}^{\prime}$ is an $m \times m$ matrix.

McAleer et al. (2008) prove that the QMLE of the parameters of the DBEKK model are consistent and asymptotically normal, so that standard statistical inference on testing hypotheses is valid. Moreover, as $Q_{t}$ in (6) can be estimated consistently, $\Gamma_{t}$ in equation (4) can also be estimated consistently.

\subsection{Testing Co-volatility Spillovers}

Chang et al. (2015) show that the DBEKK model permits a test of co-volatility spillover effects, which is the effect of a shock in commodity $j$ at $t-1$ on the subsequent co-volatility between $j$ and another commodity at $t$. Given the DBEKK model in equation (6), the subsequent co-volatility must be between commodities $j$ and $i$ at time $t$. This leads to the definition of a co-volatility spillover effect as:

$$
\frac{\partial H_{i j, t}}{\partial \varepsilon_{j, t-1}}=a_{i i} \times a_{j j} \times \varepsilon_{i, t-1}, i \neq j
$$

As $a_{i i}>0$ for all $i$, a test of the co-volatility spillover effect is a test of the significance of the estimate of $a_{i i} a_{j j}$, as $\varepsilon_{i, t-1} \neq 0$. The null hypothesis $\left(H_{0}\right)$ and the alternative hypothesis $\left(H_{1}\right)$ are as follows:

$$
\begin{aligned}
& H_{0}: a_{i i} a_{j j}=0 \\
& H_{1}: a_{i i} a_{j j} \neq 0
\end{aligned}
$$


If $H_{0}$ is rejected, there is a spillover from the returns shock of commodity $j$ at time $t-1$ to the co-volatility between commodities $i$ and $j$ at time $t$ that depends only on the returns shock of commodity $j$ at time $t-1$.

It should be emphasized that the returns shock of commodity $j$ at time $t-1$ does not affect the co-volatility spillover of commodity $j$ on the co-volatility between commodities $i$ and $j$ at time $t$. Moreover, spillovers can and do vary for each observation $t-1$, so that the empirical average co-volatility spillovers will be presented, based on the average return shocks over the sample period.

\subsection{Fundamental Equation in Tourism Finance}

McAleer (2015) developed the fundamental tourism finance equation to connect the growth in the number of tourists and the returns on the associated tourism financial asset. In this paper, we use the fundamental equation to derive the relationship between the change rate of tourist arrivals and the financial (tourism) returns, which is derived from:

$$
Y_{t}=Z_{t} \times X_{t}
$$

Consider equation (9) where total daily tourist expenditure, $y_{t}$, is equal to the daily total number of tourist arrivals, $x_{t}$, times the daily average expenditure by tourists, $z_{t}$. Taking the first difference of equation (9) will lead to equation (10), as follows:

$$
\Delta Y_{t}=\Delta Z_{t} \times \Delta X_{t}
$$

where $\Delta y_{t}=y_{t}-y_{t-1}$ is the change in total daily tourism expenditure, $\Delta x_{t}=x_{t}-$ $x_{t-1}$ is the net daily tourist arrivals, and $\Delta z_{t}=z_{t}-z_{t-1}$ is the change in the average daily expenditure by tourists. As there is little empirical evidence to suggest that the daily average expenditure by tourists changes on a daily basis (for further details, see 
McAleer, 2015), $\Delta z_{t}$ in equation (10) can be approximated by zero, in which case it follows that $\Delta y_{t}=\Delta x_{t}$ holds approximately.

Using the lagged version of equation (9) to divide the left-hand side of equation (10) by $y_{t-1}$ and the right-hand side of equation (10) by $x_{t-1}$, leads to:

$$
\frac{\Delta Y_{t}}{Y_{t-1}}=\frac{\Delta X_{t}}{X_{t-1}}
$$

where $\Delta y_{t} / y_{t-1}$ is the change rate of total daily Chinese tourism expenditure, which is the most widely used measure of financial returns in investment finance. This can be interpreted as tourism financial returns, so that $\Delta x_{t} / x_{t-1}$ is the net change rate in daily tourist arrivals.

Equation (11) is the fundamental equation in tourism finance, which shows the changes in daily returns on total tourism are approximately equal to the net change rate in daily tourist arrivals. Therefore, we use the change rate of tourist arrivals as being equivalent to the change rate of total daily Chinese tourism expenditure for purposes of the empirical analysis.

\section{Data and Variables}

Daily data for the arrivals in Taiwan of both international travellers and Chinese tourists are obtained from the National Immigration Agency of the ROC’s Ministry of Interior, and cover the period from 1 January 2014 to 31 October 2016. Given the information provided by the National Immigration Agency regarding the numbers of Chinese travellers arriving in Taiwan, there are three types of Chinese travellers, namely Group-type, Individual-type, and Medical-type.

The formula used to calculate the rate of change in the total number of tourists each day is $R_{t}=\ln \left(A_{t} / A_{t-1}\right) \times 100$, where $R_{t}$ is the rate of change in the number of tourists entering Taiwan in period $t$, and $A_{t}$ and $A_{t-1}$ are, respectively, the 
numbers of passengers arriving in Taiwan in periods $t$ and $t-1$, respectively. Each variable is described in Table 1.

\section{[Table 1 goes here]}

Table 2 presents the descriptive statistics for the rate of change in the numbers of international travellers and Chinese tourists visiting Taiwan. The standard deviation shows that the extent of the dispersion in the rate of change in the numbers of Chinese tourists coming to Taiwan is greater than for international tourists. The skewness coefficient is positive, meaning that the sequence of the rate of change in the numbers of tourist numbers is skewed to the right. The kurtosis statistic is greater than 3 , showing that the distribution has a high narrow peak, with the possibility of extreme observations. The Jarque-Bera statistic shows that none of the rankings match a normal distribution. The sequences for the three types of Chinese travellers also have the characteristics of a right-skewed distribution and high narrow peaks, and none of them seems to have a normal distribution.

\section{[Table 2 goes here]}

Figure 3 depicts the trend in terms of the numbers of tourists, and the trend in the rate of change in tourist numbers. From the numbers of tourist arrivals, it can be seen there will generally be higher numbers of visits by international travellers during the New Year holidays, whereas the numbers of Chinese tourists (especially Group-type and Individual-type tourists) have seen remarkable growth during the times when China has public holidays. This is especially the case during the Chinese National holidays (1-7 October) and the Chinese Lunar New Year holidays (31 January - 6 February, 2014, 18-24 February 2015, and 7-13 February 2016).

\section{[Figure 3 goes here]}

In addition, the numbers of Chinese tourists (especially Group-type travellers) have markedly declined since the change in government in May 2016. The trend for 
the rate of change in the numbers of tourists depicted in the second column is similar to that in the first column. The fluctuations in the numbers of both Group-type and Individual-type Chinese tourists are larger during the Chinese public holiday periods, especially during China’s National holidays (1-7 October). However, the fluctuations in the numbers of Medical-type Chinese tourists exhibit a persistent volatility clustering effect.

Following the above financial analysis, we seek to determine whether the sequence of variables is characterized by stationarity, using the Augmented Dickey-Fuller (ADF), Phillips-Perron (PP) and Kwiatkowski-Phillips-Schmidt-Shin (KPSS) tests for the existence of a unit root. The results in Table 3 show that the sequence, $R_{t}$, for the daily data on the rate of change in the number of visitors to Taiwan exhibits stationarity properties.

\section{[Table 3 goes here]}

\section{Empirical Results}

This paper has analysed the dependency relationship between Chinese tourists and international travellers visiting Taiwan, and has estimated the risk spillover effects by using the DBEKK model that has mathematical regularity conditions and valid asymptotic properties. In order to understand the effects of the interactions between the different types of Chinese tourists and international travellers, we have disaggregated the total Chinese tourists into Group-type, Individual-type, and Medical-type Chinese tourists. We analyse the dependency relationships between each of the three types of Chinese tourists and international travellers, as well as on the risk spillover effects among these various groups.

\subsection{Granger Causality and Co-volatility Spillovers Between Chinese Tourists and}




\section{International Tourists}

The upper half of Table 4 presents the dependency relationships between the rate of change in the numbers of Chinese tourists $\left(R_{C}\right)$ and the rate of change in the numbers of international travellers $\left(R_{F}\right)$. The second column shows that the impact of the rate of change in the numbers of tourist arrivals from China in the previous period $\left(R_{C}(-1)\right)$ on the numbers of international travellers in the current period $\left(R_{F}\right)$ is positive, though not significant. The third column shows that the impact of the numbers of international travellers in the previous period $\left(R_{F}(-1)\right)$ on the rate of change in the numbers of Chinese tourists arriving in the current period $\left(R_{C}\right)$ is positive, though not significant, indicating that there is no Granger causality relationship between tourists visiting Taiwan from China and international travellers.

\section{[Table 4 goes here]}

The lower part of Table 4 presents the estimated risk volatility spillover effects of the DBEKK model. The estimated parameters in matrix $A$ in the second column $(0.483,0.408)$ are significantly different from zero at the $1 \%$ significance level, indicating that the respective impacts of the rates of change in the numbers of tourists in the previous period, whether visiting Taiwan from China or from other countries, on the rates of change in the numbers of such tourists in the current period, both exhibit significant co-volatility spillover effects.

Table 5 reports the means of the impact of tourists visiting Taiwan on tourism revenue, and Table 6 reports the co-volatility spillover effects. For example, the average co-risk volatility spillover effect of $R_{F}$ on $\left(R_{C}\right.$ and $\left.R_{F}\right)$ is -0.081 , while the average co-volatility spillover effect of $R_{C}$ on $\left(R_{C}\right.$ and $\left.R_{F}\right)$ is -0.100 ,, both of which are negative.

\section{[Tables 5 and 6 go here]}




\subsection{Granger Causality and Co-volatility Spillovers Between Three Types of Chinese Tourists and International Tourists}

The upper half of Table 7 reports the interdependency relationships between the rate of change in the numbers of the three types of Chinese tourists visiting Taiwan $\left(R_{G}, R_{I}, R_{M}\right)$ and the rate of change in the numbers of international travellers $\left(R_{F}\right)$ ). There is evidence of a significant negative Granger causality relationship in terms of the impact of the rate of change in the number of international travellers in the previous period $\left(R_{F}(-1)\right)$, and the rate of change in the number of Medical-type tourists in the current period $\left(R_{M}\right)$. There is also a significant positive Granger causality relationship in terms of the impact of the rate of change in the number of Individual-type travellers in the previous period $\left(R_{I}(-1)\right)$ on the rate of change in the numbers of Group-type tourists in the current period $\left(R_{G}\right)$.

There is a significant negative Granger causality relationship in terms of the impact of the rate of change in the numbers of Medical-type tourists in the previous period $\left(R_{M}(-1)\right)$ on the rate of change in the numbers of Group-type tourists in the current period $\left(R_{G}\right)$, as well as on the rate of change in the numbers of Individual-type tourists in the current period $\left(R_{I}\right)$. In addition, a positive Granger causality relationship is found to exist in terms of the impact of the rate of change in the numbers of Group-type tourists in the previous period $\left(R_{G}(-1)\right)$ on the rate of change in the numbers of Medical-type tourists in the current period $\left(R_{M}\right)$.

The lower part of Table 7 presents the results for the risk volatility spillover effects between the rates of change in the numbers of each of the three types of Chinese tourists $\left(R_{G}, R_{I}, R_{M}\right)$ and the rate of change in the number of international travellers $\left(R_{F}\right)$. The second column of the table shows that the estimates of matrix $A$ $(0.267,0.389,0.210,0.298)$ are all significantly different from zero at the $1 \%$ 
significance level, indicating that the impact of the rate of change in the numbers of tourist arrivals in the previous period, whether Group-type, Individual-type, or Medical-type tourists from China or travellers from other countries, is significant in terms of the co-volatility spillover effects on the rate of change in the numbers of tourists in the current period.

\section{[Table 7 goes here]}

The results for the average co-volatility spillover effects are presented in Tables 8 and 9. Table 8 reports the mean values for the impact on tourism receipts from travellers visiting Taiwan, while Table 9 reports the co-volatility spillover effects. For example, the average co-volatility spillover effect of $R_{F}$ on $\left(R_{G}\right.$ and $\left.R_{F}\right)$ is -0.020 , and the average co-volatility spillover effect of $R_{G}$ on $\left(R_{G}\right.$ and $\left.R_{F}\right)$ is 0.003 . In comparing the two, we obtain the spillover effect of the absolute value. The impact of $R_{F}$ on $\left(R_{G}\right.$ and $\left.R_{F}\right)$ is greater than that of $R_{G}$ on $\left(R_{G}\right.$ and $\left.R_{F}\right)$. In addition, the co-volatility spillover effect in terms of the impact of $R_{F}$ on $\left(R_{I}\right.$ and $\left.R_{F}\right)$ is -0.036 , but the co-volatility spillover effect in terms of the impact of $R_{I}$ on $\left(R_{I}\right.$ and $\left.R_{F}\right)$ is 0.004. In comparing the two, we obtain the spillover effect of the absolute value. It is also found that the impact of $R_{F}$ on $\left(R_{I}\right.$ and $\left.R_{F}\right)$ is greater than that of $R_{I}$ on $\left(R_{I}\right.$ and $R_{F}$ ). The co-volatility spillover effect in terms of the impact of $R_{F}$ on ( $R_{M}$ and $R_{F}$ ) is 0.012 , while the co-volatility spillover effect in terms of the impact of $R_{M}$ on $\left(R_{M}\right.$ and $\left.R_{F}\right)$ is 0.002 .

\section{[Tables 8 goes here]}

The last column of Table 9 shows the risk volatility spillover effects between the rates of change in the numbers of each of the three types of Chinese tourists. The co-volatility spillover effect of $R_{G}$ on $\left(R_{G}\right.$ and $\left.R_{I}\right)$ is -0.032 , while that of $R_{I}$ on $\left(R_{G}\right.$ and $\left.R_{I}\right)$ is -0.026 . The co-volatility spillover effect of $R_{G}$ on $\left(R_{G}\right.$ and $\left.R_{M}\right)$ is 0.011 , but that of $R_{M}$ on $\left(R_{G}\right.$ and $\left.R_{M}\right)$ is -0.014 . The co-volatility spillover effect of 
$R_{I}$ on $R_{I}$ and $R_{M}$ is 0.016 , but that of $R_{M}$ on $R_{I}$ and $R_{M}$ is -0.025 . After obtaining the absolute values and comparing the impacts of the effects, it is found that the impact of $R_{M}$ on $\left(R_{G}\right.$ and $\left.R_{M}\right)$ is greater than the effect of $R_{G}$ on $\left(R_{G}\right.$ and $\left.R_{M}\right)$, and the impact of $R_{M}$ on $\left(R_{I}\right.$ and $\left.R_{M}\right)$ is greater than the impact of $R_{I}$ on $\left(R_{I}\right.$ and $\left.R_{M}\right)$.

\section{[Table 9 goes here]}

\section{Conclusion}

Since 2008 when Taiwan relaxed its Cross-Strait tourism policy, China has quickly become the largest source of international tourists visiting Taiwan. Consequently, China has also become the major country affecting the development of Taiwan’s tourism economy. The current DPP government, which took office in 2016, has not been able to satisfy China in terms of its Cross-Strait policy, and Cross-Strait relations are currently at a stalemate.

The purpose of this paper has been to understand and explain the risk volatility spillover effects between the tourism demand of Chinese tourists and international travellers visiting Taiwan in order to facilitate the risk management of Taiwan's tourism market. Using daily data for Chinese tourists and international travellers visiting Taiwan over the period 1 January 2014 to 31 October 2016, together with a diagonal BEKK multivariate conditional volatility model, we have analysed the co-volatility spillover effects between the rate of change in the numbers of international travellers and the rate of change in the numbers of Chinese tourists visiting Taiwan.

From the empirical results, we found that there is no dependency relationship between the rate of change in the numbers of Chinese tourists and the rate of change in the number of international travellers visiting Taiwan. However, there is a 
significant negative co-volatility spillover effect between the rate of change in the numbers of Chinese tourists and the rate of change in the numbers of international travellers. With the ongoing stalemate in Cross-Strait relations, and the gradual reduction in the number of Chinese tourists, it is imperative be pro-active in expanding other markets for international tourists and to attract international travellers to Taiwan. This will help reduce the impact of the reduction in the numbers of Chinese tourists and promote the continued development of Taiwan's tourism industry.

In considering the interactions between the three different types of Chinese tourists described above, and international travellers, the empirical results show that a Granger causality relationship exists between international tourists and Medical-type Chinese tourists, but there is little evidence of a Granger causality relationship between international tourists and Group-type or Individual-type Chinese tourists.

This paper also found that the co-volatility spillover effects in terms of the numbers of Group-type Chinese tourists and international travellers caused by the abnormal impact of the changes in the numbers of international travellers are greater than the co-volatility spillover effects in terms of the numbers of Group-type Chinese tourists and international travellers caused by the abnormal impact of the changes in the number of Group-type travellers. Similarly, the co-volatility spillover effects in terms of the numbers of individual-type Chinese tourists and international travellers caused by the abnormal impact of the changes in the number of international travellers are greater than the co-volatility spillover effects in terms of the numbers of Individual-type Chinese tourists and international travellers caused by the abnormal impact of the changes in the number of individual-type travellers.

From these empirical results, it can be inferred that when the numbers of both Group-type and Individual-type tourists decrease, the government can promote 
tourism policies that increase the numbers of international travellers visiting Taiwan, so as to lessen the impact of the decline in the numbers of Group-type and Individual-type tourists on Taiwan's tourism market.

In addition, both Group-type and Individual-type travellers have a significant negative co-volatility spillover effect on the rate of change in the numbers of Group-type and Individual-type tourist arrivals. It was also found that the abnormal impact of changes in the number of Medical-type travellers on the co-volatility spillover effects of Group-type and Medical-type travellers was greater than the abnormal impact of changes in the numbers of Group-type travellers on the co-volatility spillover effects of Group-type and Medical-type travellers.

At the same time, the abnormal impact of changes in the numbers of Medical-type travellers on the co-volatility spillover effects of Individual-type and Medical-type travellers was greater than the abnormal impact of changes in the numbers of Individual-type travellers on the co-volatility spillover effects of Individual-type and Medical-type travellers. From this it can be inferred that, as the numbers of Chinese tourists decline, especially in cases where the numbers of Group-type and Medical-type travellers decrease significantly, by actively taking steps to increase the numbers of Individual-type Chinese tourists visiting Taiwan, it would be possible for the government to reduce the adverse impact brought about by the reduction in the overall number of Chinese tourists.

The empirical results from the paper would suggest that Taiwan should abandon its development strategy of only focusing on a single market, namely China, and have an objective to be pro-active in encouraging visits by international travellers to Taiwan for sightseeing purposes. Such a strategy would increase the willingness of international travellers to visit Taiwan.

In addition, with the reduction in the numbers of Chinese tour groups visiting 
Taiwan, and the increase in the number of individual travellers, the Taiwan Government should change its previous travel policies of focusing on attracting Chinese tour group travellers and actively promoting in-depth tourism among international tourists, by developing tourism that focuses on the special characteristics of different localities. In this way, such a tourism policy could enhance the quality of Taiwan's tourism, and also attract travellers with high spending power. 
Figure 1

Taiwan's International Tourism Receipts and Growth Rate from 2000 to 2016

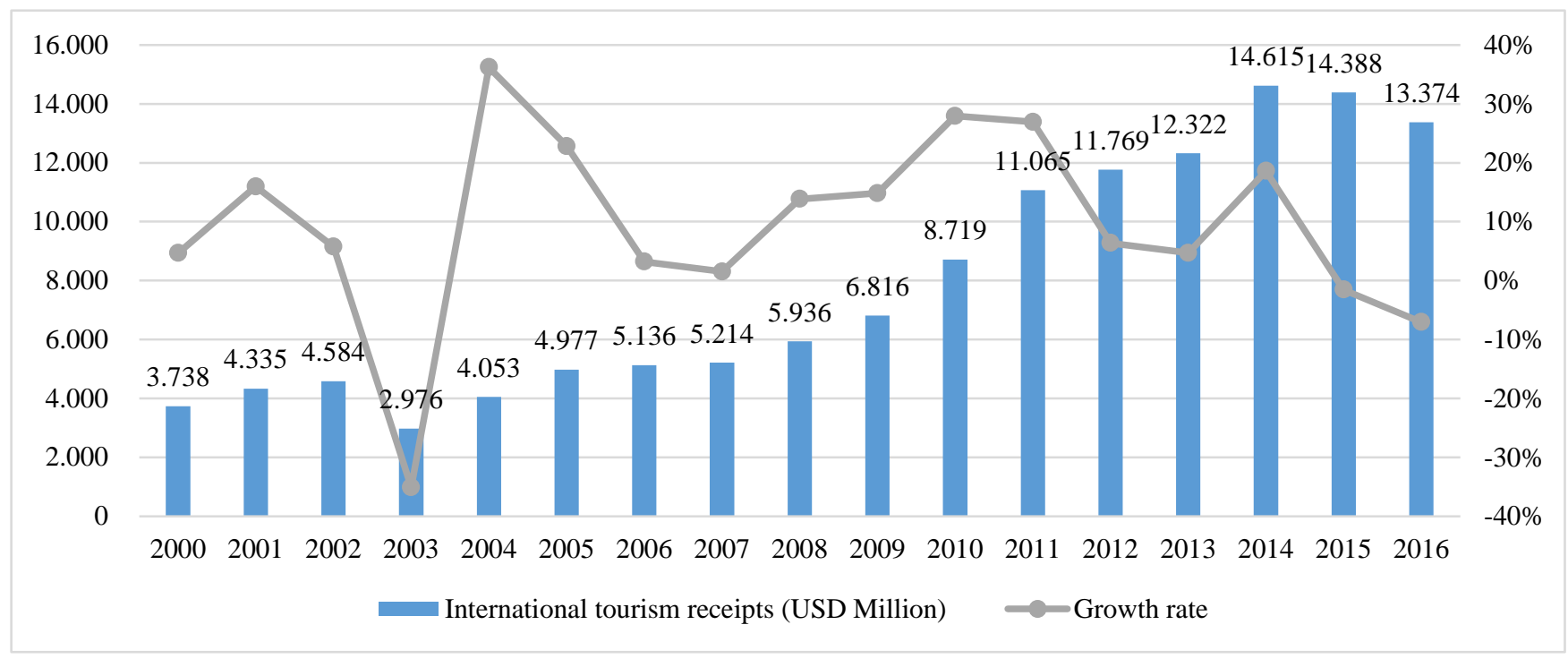

Source: Taiwan Tourism Bureau (2017). 
Figure 2

International and Chinese Tourist Arrivals from 2008 to 2016

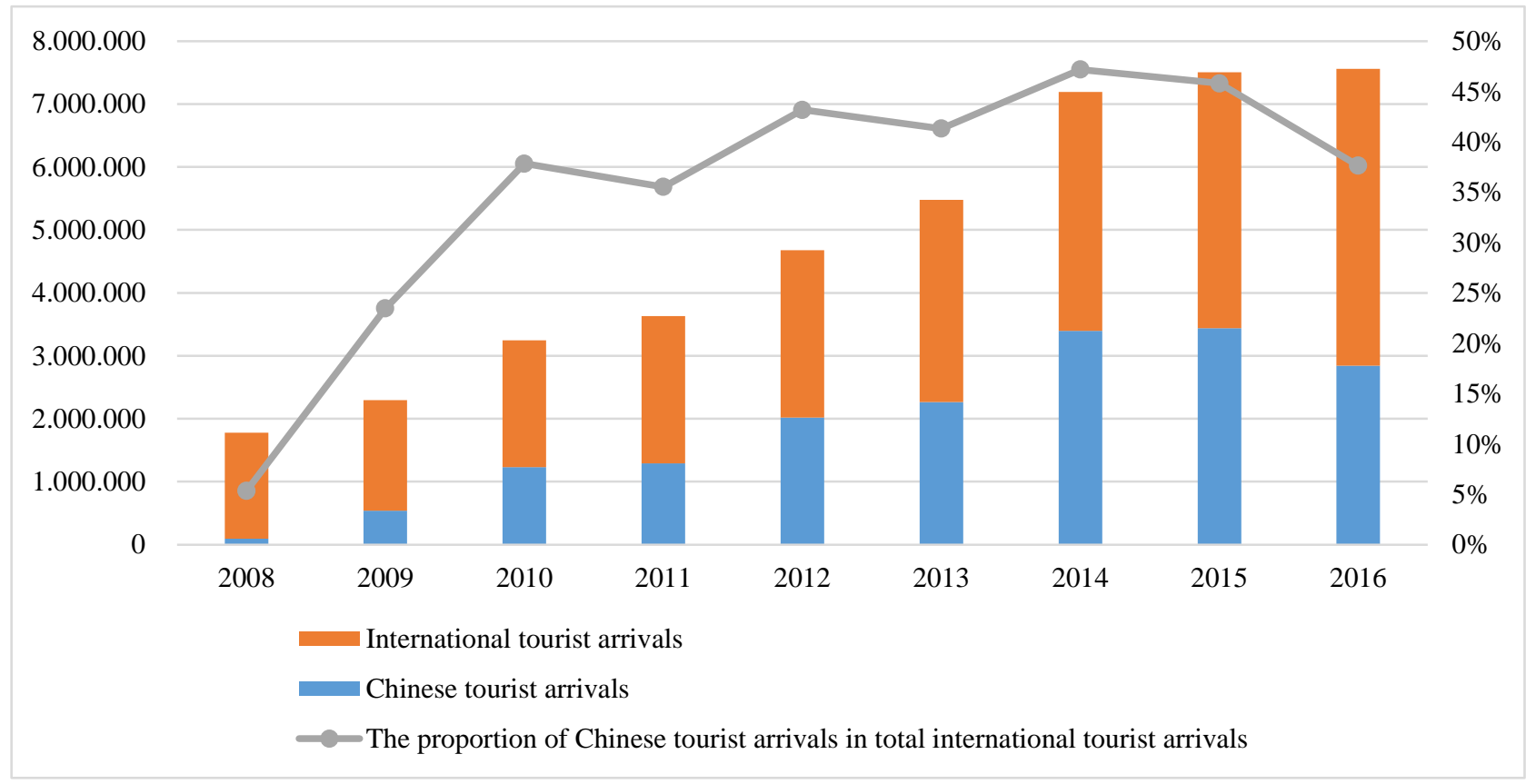

Source: Taiwan Tourism Bureau (2017). 
Figure 3

Daily Tourist Arrivals and Their Change Rate to Taiwan

from $2014 / 1 / 1$ to $2016 / 10 / 31$

Total tourist arrivals

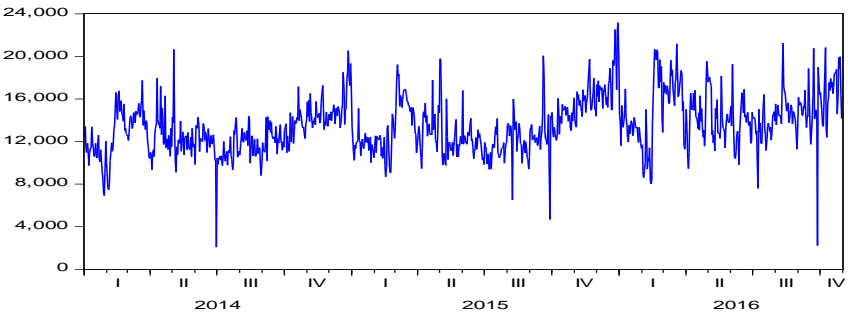

International tourists

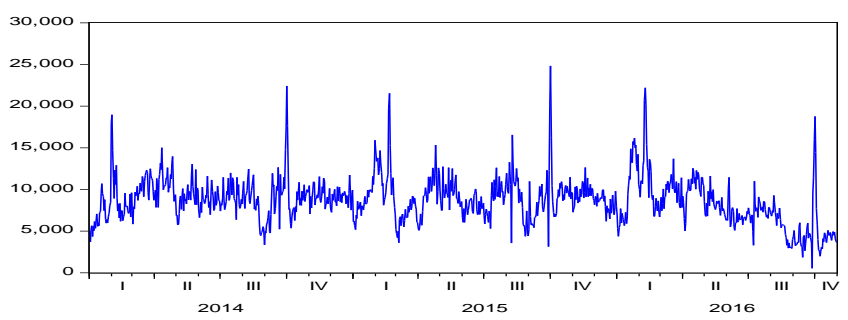

Total Chinese tourists

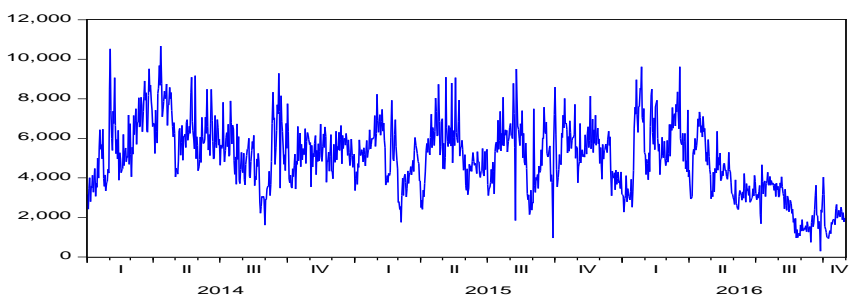

Group-type Chinese tourists

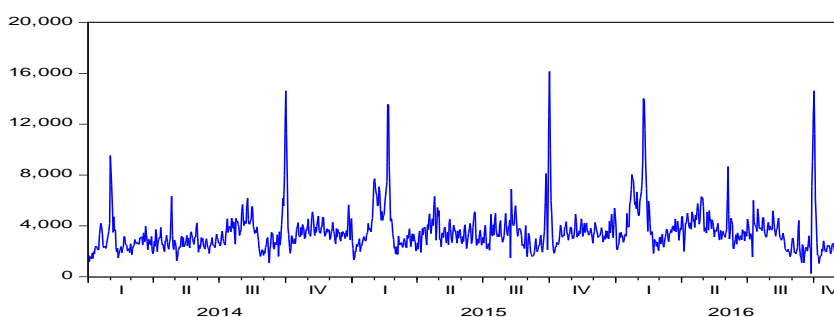

Individual-type Chinese tourists

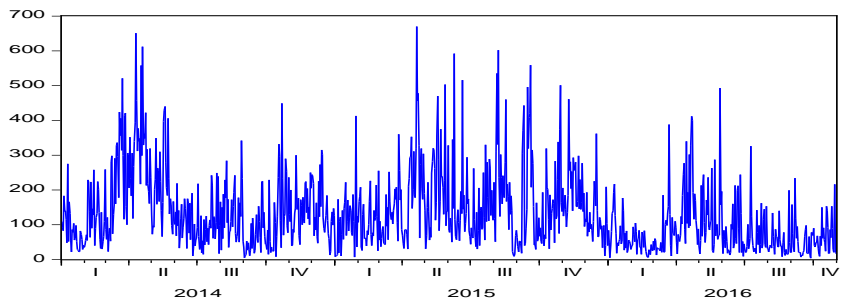

Medical-type Chinese tourists
Change rate of total tourist arrivals

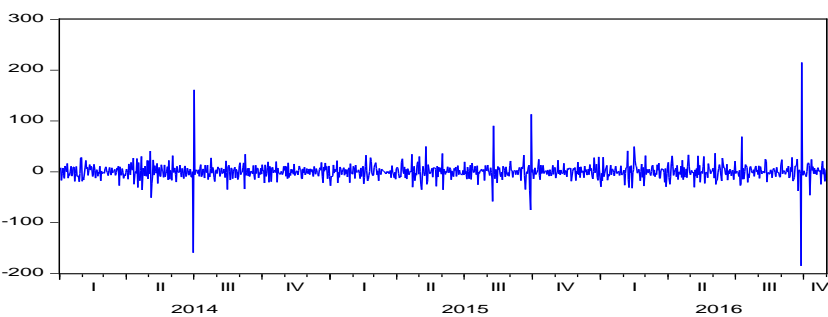

Change rate of international tourists

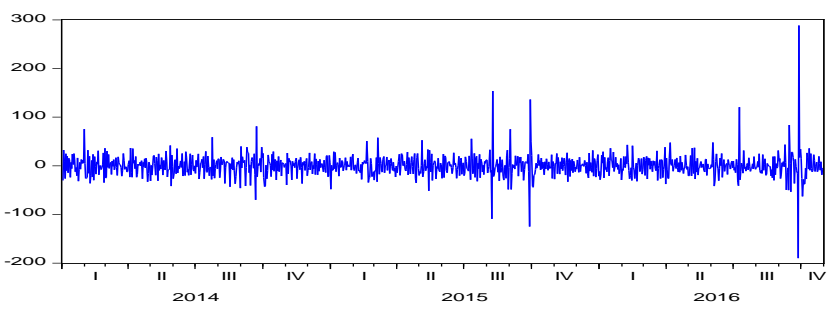

Change rate of total Chinese tourists

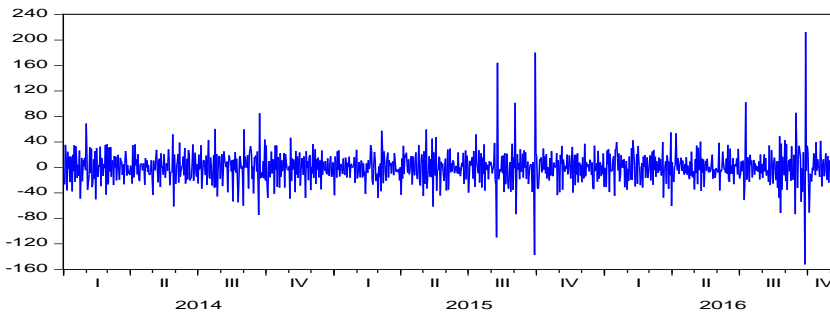

Change rate of Group-type Chinese tourists

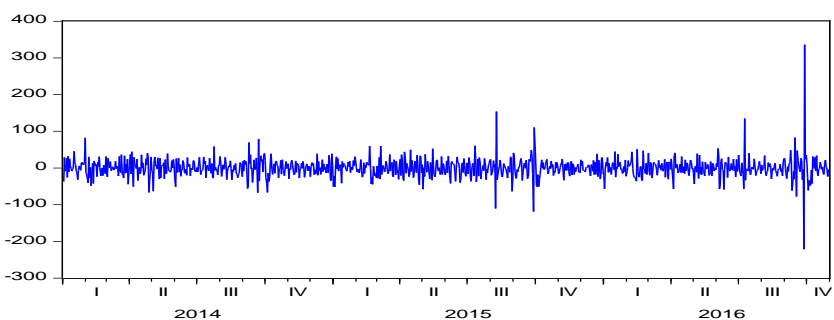

Change rate of Individual-type Chinese tourists

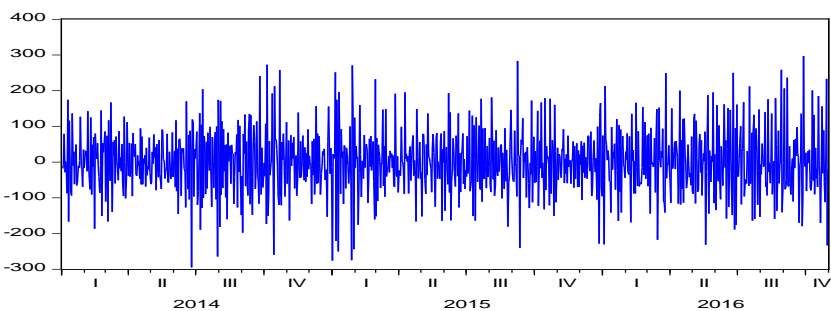

Change rate of Medical-type Chinese tourists 
Table 1

Definitions of Variables

\begin{tabular}{c|l}
\hline Variables & \multicolumn{1}{c}{ Definition } \\
\hline$R_{F}$ & Change rate of international tourist arrivals to Taiwan \\
\hline$R_{C}$ & Change rate of total Chinese tourist arrivals to Taiwan \\
\hline$R_{G}$ & Three Types of Chinese tourists \\
$R_{I}$ & Change rate of Group-type Chinese tourist arrivals to Taiwan \\
$R_{M}$ & Change rate of Individual-type Chinese tourist arrivals to Taiwan \\
\hdashline$\cdots \cdots$ & Change rate of Medical-type Chinese tourist arrivals to Taiwan \\
\hline
\end{tabular}


Table 2

Descriptive Statistics

\begin{tabular}{|c|c|c|c|c|c|}
\hline \multirow{2}{*}{$\begin{array}{l}\text { Descriptive } \\
\text { Statistics }\end{array}$} & \multirow{2}{*}{$\begin{array}{c}\text { International } \\
\text { Tourists }\end{array}$} & \multirow{2}{*}{$\begin{array}{l}\text { Chinese } \\
\text { Tourists }\end{array}$} & \multicolumn{3}{|c|}{ Three Types of Chinese Tourists } \\
\hline & & & Group & Individual & Medical \\
\hline & $R_{F}$ & $R_{C}$ & $R_{G}$ & $R_{I}$ & $R_{M}$ \\
\hline Mean & 0.017 & -0.031 & -0.051 & 0.001 & -0.180 \\
\hline Median & -0.219 & -0.030 & -0.060 & -0.457 & -2.643 \\
\hline Maximum & 214.19 & 288.30 & 212.20 & 336.13 & 297.04 \\
\hline Minimum & -185.84 & -189.84 & -152.38 & -221.33 & -294.97 \\
\hline Std. Dev. & 17.39 & 23.07 & 24.99 & 26.34 & 88.76 \\
\hline Skewness & 0.984 & 1.790 & 0.805 & 1.638 & 0.145 \\
\hline Kurtosis & 53.00 & 34.94 & 14.56 & 35.06 & 3.60 \\
\hline Jarque-Bera & 107887 & 44490 & 5870 & 44733 & 18.95 \\
\hline Probability & 0 & 0 & 0 & 0 & 0 \\
\hline Sum & 17.193 & -31.838 & -52.63 & 1.38 & -185.81 \\
\hline Sum Sq. Dev. & 312476 & 549859 & 645182 & 716550 & 8138389 \\
\hline No. observations & 1034 & 1034 & 1034 & 1034 & 1034 \\
\hline
\end{tabular}


Table 3

Unit Root Tests

\begin{tabular}{|c|c|c|c|}
\hline \multirow{2}{*}{ Variables } & \multicolumn{3}{|c|}{ ADF test } \\
\hline & no trend and intercept & with intercept & with trend and intercept \\
\hline$R_{F}$ & $-20.34 *$ & $-20.34 *$ & $-20.34 *$ \\
\hline$R_{C}$ & $-19.41^{*}$ & $-19.40 *$ & $-19.41^{*}$ \\
\hline \multicolumn{4}{|c|}{ Three types of Chinese Tourists } \\
\hline$R_{G}$ & $-14.90 *$ & $-14.90 *$ & $-14.91 *$ \\
\hline$R_{I}$ & $-15.24 *$ & $-15.23 *$ & $-15.24 *$ \\
\hline$R_{M}$ & $-19.54 *$ & $-19.53 *$ & $-19.52 *$ \\
\hline \multirow{2}{*}{ Variables } & \multicolumn{3}{|c|}{ PP test } \\
\hline & no trend and intercept & with intercept & with trend and intercept \\
\hline$R_{F}$ & $-151.73^{*}$ & $-151.95^{*}$ & $-151.94 *$ \\
\hline$R_{C}$ & $-104.20 *$ & $-104.23^{*}$ & $-112.30 *$ \\
\hline \multicolumn{4}{|c|}{ Three types of Chinese Tourists } \\
\hline$R_{G}$ & $-111.90 *$ & $-112.66^{*}$ & $-124.12 *$ \\
\hline$R_{I}$ & $-79.35 *$ & $-79.27 *$ & $-80.91 *$ \\
\hline$R_{M}$ & $-284.46^{*}$ & $-307.89^{*}$ & $-377.68^{*}$ \\
\hline \multirow{2}{*}{ Variables } & \multicolumn{3}{|c|}{ KPSS test } \\
\hline & with intercept & & with trend and intercept \\
\hline$R_{F}$ & $0.055^{+}$ & & $0.054^{+}$ \\
\hline$R_{C}$ & $0.358^{+}$ & & $0.126^{+}$ \\
\hline \multicolumn{4}{|c|}{ Three types of Chinese Tourists } \\
\hline$R_{G}$ & $0.207^{+}$ & & $0.059^{+}$ \\
\hline$R_{I}$ & $0.169^{+}$ & & $0.056^{+}$ \\
\hline$R_{M}$ & $0.308^{+}$ & & $0.240^{+}$ \\
\hline
\end{tabular}

Notes : 1. ADF and PP, respectively, denote the Augmented Dickey-Fuller test and Phillips-Perron test, with null hypothesis that the variable has a unit root, while KPSS denotes the Kwiatkowski-Phillips-Schmidt-Shin test with null hypothesis that the variable is stationary.

2. * denotes rejection of the null hypothesis at the $1 \%$ level of significance. 
Table 4

Diagonal BEKK for Chinese and International Tourists

\begin{tabular}{c|c|c}
\hline & \multicolumn{2}{|c}{ Mean } \\
\hline Variables & $R_{C}$ & $R_{F}$ \\
\hline \multirow{2}{*}{$R_{C}(-1)$} & $-0.266^{*}$ & 0.0001 \\
& $(0.037)$ & $(0.024)$ \\
$R_{F}(-1)$ & 0.008 & $-0.248^{*}$ \\
& $(0.039)$ & $(0.041)$ \\
constant & 0.401 & 0.519 \\
& $(0.610)$ & $(0.482)$ \\
\hline
\end{tabular}

Diagonal BEKK

\begin{tabular}{|c|c|c|c|c|c|c|}
\hline Variables & \multicolumn{2}{|c|}{$\mathrm{C}$} & \multicolumn{2}{|c|}{ A } & \multicolumn{2}{|c|}{ B } \\
\hline$R_{C}$ & $\begin{array}{l}150.41 * \\
(22.60)\end{array}$ & $\begin{array}{l}32.42 * \\
(4.82)\end{array}$ & $\begin{array}{l}0.483 * \\
(0.035)\end{array}$ & & $\begin{array}{l}0.664^{*} \\
(0.051)\end{array}$ & \\
\hline$R_{F}$ & & $\begin{array}{l}46.06 * \\
(6.37)\end{array}$ & & $\begin{array}{l}0.408 * \\
(0.031)\end{array}$ & & $\begin{array}{l}0.813^{*} \\
(0.022)\end{array}$ \\
\hline
\end{tabular}

Log-likelihood $\quad-8704.4$

AIC $\quad 16.88$

Notes: 1. $\mathrm{A}=\left[\begin{array}{cc}a_{11} & 0 \\ 0 & a_{22}\end{array}\right], \mathrm{B}=\left[\begin{array}{cc}b_{11} & 0 \\ 0 & b_{22}\end{array}\right], \mathrm{C}=\left[\begin{array}{cc}c_{11} & c_{12} \\ 0 & c_{22}\end{array}\right]$

2. * denote significance at the $1 \%$ level. Standard errors are in parentheses. 
Table 5

Average Return Shocks for Chinese and International Tourists

\begin{tabular}{cc}
\hline Variables & Average of return shocks \\
\hline$R_{C}$ & -0.410 \\
$R_{F}$ & -0.507
\end{tabular}

Table 6

Average Co-volatility Spillovers between Chinese and International Tourists

\begin{tabular}{ccc}
\hline Variables i & Variables j & Average Co-volatility Spillovers \\
\hline$R_{C}$ & $R_{F}$ & $-0.081^{*}(=0.483 \times 0.408 \times-0.410)$ \\
$R_{F}$ & $R_{C}$ & $-0.100 *(=0.483 \times 0.408 \times-0.507)$ \\
\hline
\end{tabular}


Table 7

Diagonal BEKK for Three Types of Chinese Tourists and International Tourists

\begin{tabular}{c|c|c:c:c}
\hline \multicolumn{3}{|c}{ Mean } & \multicolumn{1}{c}{} \\
\hline Variables & $R_{G}$ & $R_{I}$ & $R_{M}$ & $R_{F}$ \\
\hline \multirow{2}{*}{$R_{G}(-1)$} & $-0.407^{*}$ & -0.048 & $0.317^{*}$ & 0.023 \\
& $(0.036)$ & $(0.037)$ & $(0.120)$ & $(0.027)$ \\
$R_{I}(-1)$ & $0.127^{*}$ & -0.040 & 0.110 & -0.005 \\
& $(0.036)$ & $(0.043)$ & $(0.129)$ & $(0.025)$ \\
$R_{M}(-1)$ & $-0.021^{*}$ & $-0.023^{*}$ & $-0.392^{*}$ & -0.003 \\
& $(0.008)$ & $(0.008)$ & $(0.031)$ & $(0.006)$ \\
$R_{F}(-1)$ & -0.033 & 0.036 & $-0.371^{* *}$ & $-0.120 *$ \\
& $(0.045)$ & $(0.052)$ & $(0.184)$ & $(0.042)$ \\
C & 0.120 & 0.340 & -0.401 & -0.021 \\
& $(0.694)$ & $(0.759)$ & $(2.378)$ & $(0.537)$ \\
\hline
\end{tabular}

Diagonal BEKK

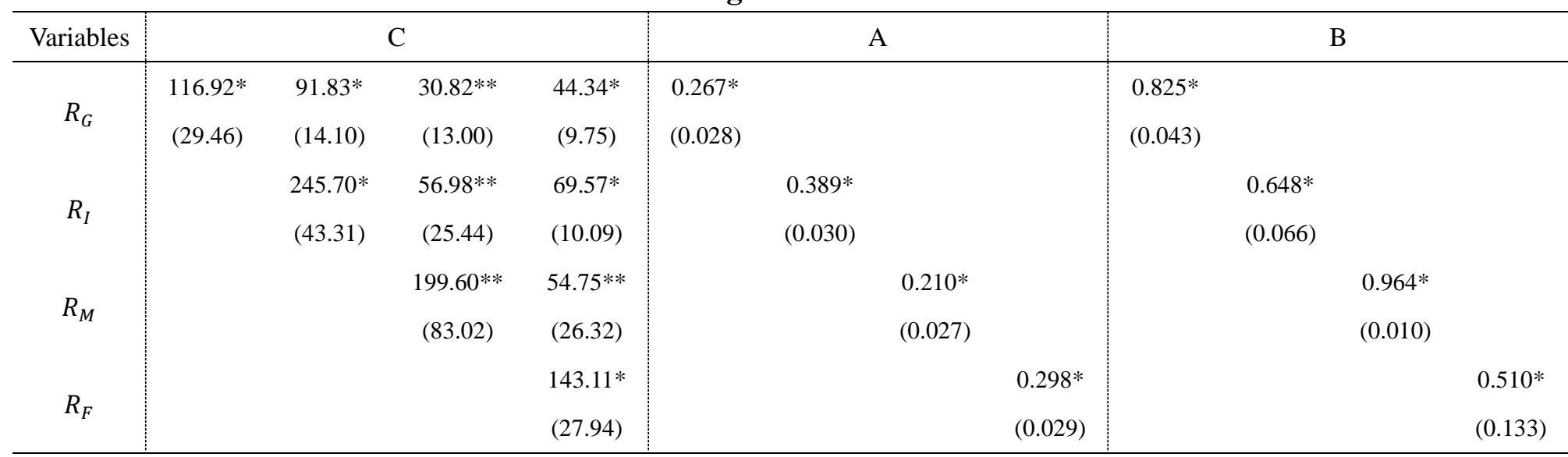

Log-likelihood $\quad$-19347.2

AIC 37.53

Notes: 1. $\mathrm{A}=\left[\begin{array}{llll}a_{11} & 0 & 0 & 0 \\ 0 & a_{22} & 0 & 0 \\ 0 & 0 & a_{33} & 0 \\ 0 & 0 & 0 & a_{44}\end{array}\right], \mathrm{B}=\left[\begin{array}{llll}b_{11} & 0 & 0 & 0 \\ 0 & b_{22} & 0 & 0 \\ 0 & 0 & b_{33} & 0 \\ 0 & 0 & 0 & b_{44}\end{array}\right]$, $\mathrm{C}=\left[\begin{array}{llll}c_{11} & c_{12} & c_{13} & c_{14} \\ 0 & c_{22} & c_{23} & c_{24} \\ 0 & 0 & c_{33} & c_{34} \\ 0 & 0 & 0 & c_{44}\end{array}\right]$

2. * and $* *$ denote significance at the $1 \%$ and $5 \%$ levels, respectively.

Standard errors are in parentheses. 
Table 8

Average Return Shocks for three types of Chinese Tourists and International

Tourists

\begin{tabular}{cc}
\hline Variables & Average Return Shocks \\
\hline$R_{G}$ & -0.247 \\
$R_{I}$ & -0.309 \\
$R_{M}$ & 0.195 \\
$R_{F}$ & 0.033 \\
\hline
\end{tabular}

Table 9

Average Co-volatility Spillovers for Three Types of

Chinese Tourists and International Tourists

\begin{tabular}{ccc}
\hline Variables i & Variables j & Average Co-volatility Spillovers \\
\hline$R_{G}$ & $R_{F}$ & $-0.020^{*}(=0.267 \times 0.298 \times-0.247)$ \\
$R_{F}$ & $R_{G}$ & $0.003^{*}(=0.267 \times 0.298 \times 0.033)$ \\
$R_{I}$ & $R_{F}$ & $-0.036^{*}(=0.389 \times 0.298 \times-0.309)$ \\
$R_{F}$ & $R_{I}$ & $0.004^{*}(=0.389 \times 0.298 \times 0.033)$ \\
$R_{M}$ & $R_{F}$ & $0.012^{*}(=0.210 \times 0.298 \times 0.195)$ \\
$R_{F}$ & $R_{M}$ & $0.002^{*}(=0.210 \times 0.298 \times 0.033)$ \\
$R_{G}$ & $R_{I}$ & $-0.026^{*}(=0.267 \times 0.389 \times-0.247)$ \\
$R_{I}$ & $R_{G}$ & $-0.032^{*}(=0.267 \times 0.389 \times-0.309)$ \\
$R_{G}$ & $R_{M}$ & $-0.014^{*}(=0.267 \times 0.210 \times-0.247)$ \\
$R_{M}$ & $R_{G}$ & $0.011^{*}(=0.267 \times 0.210 \times 0.195)$ \\
$R_{I}$ & $R_{M}$ & $-0.025^{*}(=0.389 \times 0.210 \times-0.309)$ \\
$R_{M}$ & $R_{I}$ & $0.016^{*}(=0.389 \times 0.210 \times 0.195)$ \\
\hline
\end{tabular}

Notes: 1 . Co-volatility Spillover $=\frac{\partial H_{i j, t}}{\partial \varepsilon_{j, t-1}}=a_{i i} \times a_{j j} \cdot \varepsilon_{i, t-1}$

2. * denotes significance at the $1 \%$ level. 


\section{References}

Akar, C., 2012, "Modelling Turkish Tourism Demand and the Exchange Rate: The Bivariate GARCH Approach”, European Journal of Economics, Finance and Administrative Sciences, 50, 133-141.

Baba, Y., R.F. Engle, D. Kraft and K.F. Kroner, 1985, "Multivariate Simultaneous Generalized ARCH”, Unpublished paper, Department of Economics, University of California, San Diego, CA, USA.

Balli, F. and W.H.K. Tsui, 2016, “Tourism Demand Spillovers between Australia and New Zealand: Evidence from the Partner Countries”, Journal of Travel Research, 55(6), 804-812.

Balli, F., J. Curry, and H.O. Balli, 2015, "Inter-regional Spillover Effects in New Zealand International Tourism Demand,” Tourism Geographies, 17(2), 262-278.

Bollerslev, T., 1990, "Modelling the Coherence in Short-run Nominal Exchange Rate: A Multivariate Generalized ARCH Approach”, Review of Economics and Statistics, 72(3), 498-505.

Chan, F., C. Lim, and M. McAleer, 2005, "Modelling Multivariate International Tourism Demand and Volatility”, Tourism Management, 26(3), 459-471.

Chang, C.-L. and M. McAleer, 2017, “The Correct Regularity Condition and Interpretation of Asymmetry in EGARCH”, Economics Letters, 161, 52-55.

Chang C.-L. and M. McAleer, 2018, “The Fiction of Full BEKK: Pricing Fossil Fuels and Carbon Emissions”, to appear in Finance Research Letters.

Chang, C.-L., M. McAleer, and Y.A. Wang, 2018, "Modelling Volatility Spillovers for Bio-ethanol, Sugarcane and Corn Spot and Futures Prices”, Renewable and Sustainable Energy Reviews, 81(1), 1002-1018.

Chang, C.-L., T. Khamkaew, R. Tansuchat, and M. McAleer, 2011, “Interdependence of International Tourism Demand and Volatility in Leading ASEAN Destinations”, Tourism Economics, 17(3), 481-507. 
Chang, C.-L., Y.-Y. Li, and M. McAleer, 2015, "Volatility Spillovers between Energy and Agricultural Markets: A Critical Appraisal of Theory and Practice”, Tinbergen Institute Discussion Papers 15-077/III, Tinbergen Institute.

Engle, R.F. and K.F. Kroner, 1995, “Multivariate Simultaneous Generalized ARCH”, Econometric Theory, 11(1), 122-150.

Engle, R.F., 1982, “Autoregressive Conditional Heteroscedasticity with Estimates of the Variance of United Kingdom Inflation”, Econometrica, 50(4), 987-1007.

Engle, R., 2002, “Dynamic Conditional Correlation: A Simple Class of Multivariate Generalized Autoregressive Conditional Hereoskedasticity Models”, Journal of Business and Economic Statistics, 20(3), 339-350.

Hoti, S., M. McAleer, and R. Shareef, 2007, “Modelling International Tourism and Country Risk Spillovers for Cyprus and Malta”, Tourism Management, 28(6), 1472-1484.

Ling, S. and M. McAleer, 2003, “Asymptotic Theory for a Vector ARMA-GARCH Model”, Econometric Theory, 19(2), 280-310.

McAleer, M., 2005, “Automated Inference and Learning in Modeling Financial Volatility”, Econometric Theory, 21(1), 232-261.

McAleer, M., 2014, “Asymmetry and Leverage in Conditional Volatility Models”, Econometrics, 2(3), 145-150.

McAleer, M., 2015, “The Fundamental Equation in Tourism Finance”, Journal of Risk and Financial Management, 8(4), 369-374.

McAleer, M., 2018, “Stationarity and Invertibility of a Dynamic Correlation Matrix”, to appear in Kybernetika.

McAleer, M., F. Chan, S. Hoti and O. Lieberman, 2008, “Generalized Autoregressive Conditional Correlation”, Econometric Theory, 24(6), 1554-1583.

McAleer, M. and Hafner, C. (2014), A One Line Derivation of EGARCH, Econometrics, 2(2), 92-97. 
McAleer, M., S. Hoti, and F. Chan, 2009, "Structure and Asymptotic Theory for Multivariate Asymmetric Conditional Volatility”, Econometric Reviews, 28(5), 422-440.

National Immigration Agency of Taiwan, “Statistical Data”, Retrieved 11 December, 2017, from: http://www.immigration.gov.tw/mp.asp?mp=1. (in Chinese)

Seo, J. H., S. Y. Park, and L. Yu, 2009, "The Analysis of the Relationships of Korean Outbound Tourism Demand: Jeju Island and Three International Destinations”, Tourism Management, 30(4), 530-543.

Shareef, R. and M. McAleer, 2008, "Modelling International Tourism Demand and Uncertainty in Maldives and Seychelles: A Portfolio Approach”, Mathematics and Computers in Simulation, 78(2), 459-468.

Taiwan Tourism Bureau, 2017, “Statistic Data”, Retrieved 11 December, 2017, form http://admin.taiwan.net.tw/. (in Chinese)

Tsay, R.S., 1987, “Conditional Heteroscedastic Time Series Models”, Journal of the American Statistical Association, 82(398), 590-604.

UNWTO, 2017, “UNWTO Tourism Highlights, 2017 Edition”, Retrieved 11 December, 2017, from: https://www.e-unwto.org/doi/pdf/10.18111/9789284419029.

Valadkhani, A., R. Smyth, and B. O’Mahony, 2017, “Asymmetric Causality between Australian Inbound and Outbound Tourism Flows”, Applied Economics, 49(1), 33-50.

WEF, 2017, “Travel and Tourism Competitiveness Report”, Retrieved 11 December, 2017, from: http://www3.weforum.org/docs/WEF_TTCR_2017_web_0401.pdf.

WTTC, 2017, “Travel \& Tourism Economic Impact 2016 Taiwan”, Retrieved 11 December, 2017, from: https://www.wttc.org/-/media/files/reports/economic-impact-research/countries2017/taiwan2017.pdf.

Yap, G.C.L., 2012, “An Examination of the Effects of Exchange Rates on Australia’s Inbound Tourism Growth: A Multivariate Conditional Volatility Approach”, 
International Journal of Business Studies, 20(1), 111-132. 